\title{
DETERMINATION OF QUALITY OF LIFE IN ADULT PATIENTS WITH MODERATE-TO-SEVERE ASTHMA
}

\author{
Vijay Devdas Nair ${ }^{1}$, Seema K²
}

${ }^{1}$ Assistant Professor, Department of Pulmonary Medicine, Krishna Institute of Medical Sciences, Karad. ${ }^{2}$ Consultant Pulmonologist, PVS Memorial Hospital, Kochi.

\section{ABSTRACT}

\section{BACKGROUND}

One of the primary goals in the treatment of obstructive lung disease is to improve the health-related quality of life (HRQL) of patients. In the current cross-sectional study, we have attempted to identify the traditional physiological and clinical parameters that are independent determinants of Health Related Quality of Life (HRQL) in adult patients with moderate-to-severe asthma.

\section{MATERIALS AND METHODS}

This is a cross-sectional study. 89 asthmatic patients who fulfilled the inclusion and exclusion criteria during the allotted study period were enrolled in the study after obtaining their due consent. Diagnosis of asthma and its severity was based on guidelines set by GINA. They were then made to perform spirometer test as per standard guidelines. They were then handed out two questionnaires, junipers asthma quality of life questionnaire and a questionnaire to assess determinants of asthma. The data of the present study was nominal; therefore Pearson's chi-square test was applied. The data was considered statistically significant at 95\% confidence interval. The data was analysed using SPSS version 11.

\section{RESULTS}

Mean age of population was 48.25 years with standard deviation of $+/-15.64 ; 26.66 \%$ patients having average quality of life and $52.9 \%$ patients with good quality of life were using MDI with spacer. Similarly, $85 \%$ patients with history of allergy had an average quality of life and both are statistically significant. $43 \%$ of patients with moderate obstruction had an average quality of life, though not statistically significant.

\section{CONCLUSION}

From the present study, it was concluded that though most of the parameters other than drug delivery devices and history of allergy when compared with quality of life was statistically not significant. Though the findings were not statistically significant, the data from the study belonged to average-to-poor quality of life. This warrants further study with a larger sample size.

\section{KEYWORDS}

Asthma, Health Related Quality of Life, Spirometry, Peak Expiratory Flow (PEF), Standardised Asthma Quality of Life Questionnaire (AQLQ-S).

HOW TO CITE THIS ARTICLE: Nair VD, Seema K. Determination of quality of life in adult patients with moderate-to-severe asthma. J. Evolution Med. Dent. Sci. 2018;7(03):367-371, DOI: 10.14260/jemds/2018/81

\section{BACKGROUND}

Asthma is a chronic disease that is prevalent in India and many other developed and developing countries. There is evidence that its prevalence increased in many countries during the latter part of the twentieth century.

One of the primary goals in the treatment of obstructive lung disease is to improve the health-related quality of life (HRQL) of patients. With the advent of valid, reliable and responsive questionnaires designed to measure HRQL,1-5 it has been shown that traditional clinical parameters such as lung function that focus on airflow obstruction have variable strengths of association with HRQL, even though the primary pathobiology of the disease condition is airway obstruction. It has been hypothesised that complex entities such as adverse effects from medication use, anxiety, depression and patient's

'Financial or Other Competing Interest': None.

Submission 08-12-2017, Peer Review 01-1-2018,

Acceptance 06-01-2018, Published 13-01-2018.

Corresponding Author:

Dr. Vijay Devdas Nair,

Assistant Professor

Department of TB and Chest,

Krishna Institute of Medical Sciences,

Malkapur-415539, Karad.

E-mail: devijaynair@gmail.com

DOI: $10.14260 /$ jemds $/ 2018 / 81$ satisfaction with care are captured by HRQL measurements, but not by conventional physiological and clinical outcomes. These findings have led to the recommendation that HRQL should be measured as an independent outcome.1-3 Nevertheless, outcomes of efficacy and effectiveness in asthma clinical trials and in clinical practice have focused on improvement in asthma control, as measured by FEV1 and peak flow, symptom scores and requirement for the use of reliever medication with little attention to HRQL.6-9 In fact, the National Asthma Education and Prevention Program (NAEPP) defines asthma severity before treatment by lung function and symptoms; it does not include HRQL.10,11 It has been assumed, but never demonstrated that improvement in these measures of asthma would translate into improvements in HRQL.

In the current cross-sectional study, we have attempted to identify the traditional physiological and clinical parameters that are independent determinants of Health Related Quality of Life (HRQL) in adult patients with moderate-to-severe asthma.

\section{Aims and Objectives}

To determine the quality of life of adult patients with moderate to severe asthma using Standardized Asthma Quality of Life Questionnaire (AQLQ-S). 
To find out the association between various determinants of asthma and quality of life using AQLQ-S score.

To find out the association between lung function testing [Forced Expiratory Volume (FEV1)] and Quality of life using AQLQ-S score.

\section{MATERIALS AND METHODS}

This is cross-sectional study, survey was carried out at Amrita Institute of Medical Sciences and Research Centre (AIMS), a tertiary care referral centre, Kerala, after due approval of the ethical committee. The duration of the study was between January 2008 and December 2008.

\section{Study Population}

Patients who attended the Outpatients Department in Pulmonary Medicine of Amrita Institute of Medical Sciences and Research Centre.

\section{Sample Size}

All asthmatics patients fulfilling the eligibility criteria, attending the pulmonary medicine OPD during the study period was recruited.

\section{Inclusion Criteria}

- Age above 18 years of age.

- $\mathrm{He} / \mathrm{she}$ must have a documented history of asthma for at least last 1 year.

- At time of screening, patient must be on a high dose of inhaled steroid equivalent to Budesonide $800 \mathrm{mcg} /$ day or fluticasone $1000 \mathrm{mcg} /$ day and LABA and fits with GINA classification of moderate or severe persistent asthma.

- $\mathrm{He} /$ she must be a non-smoker.

\section{Exclusion Criteria}

1. Current smokers and those who have recently quit within past 6 months.

2. Recent exacerbations [last 1 month].

3. Co-existing structural lung disease.

4. Co-existing disease involving systemic organ dysfunction.

\section{Working Definition of Asthma}

\section{Presence of any of these Signs and Symptoms}

Wheezing- high-pitched whistling sounds when breathing out especially in children.

\section{History of any of the following}

- Cough, worse particularly at night.

- Recurrent wheeze.

- Recurrent difficulty breathing.

- Recurrent chest tightness.

- Symptoms occur or worsen at night, awakening the patient.

- Symptoms occur or worsen in a seasonal pattern.

- History of eczema, hay fever or a family history of asthma or atopic diseases.

\section{Spirometer}

An increase in FEV1 of $12 \%$ and $200 \mathrm{~mL}$ after administration of a bronchodilator.

\section{Peak Expiratory Flow (PEF)}

An improvement of $60 \mathrm{~L} / \mathrm{min}$ (or $20 \%$ of the prebronchodilator PEF) after inhalation of a bronchodilator or diurnal variation in PEF of more than $20 \%$ (with twice-daily readings, more than $10 \%)$.

\section{Patient Recruitment and Data Collection}

Patients with moderate and severe persistent asthma were enrolled in our study. ${ }^{8} \mathrm{~A}$ written informed consent was taken from all patients before enrolment. They were then made to perform spirometry test. They were then handed out two questionnaires, junipers asthma quality of life questionnaire and a questionnaire to assess determinants of asthma.

\section{Pulmonary Function Measurements}

All subjects performed spirometry on a Cosmed microQuark system. FEV1 and PEF was measured using American Thoracic Society guidelines, and the highest measurements from among three technically acceptable and reproducible manoeuvres were expressed at body temperature and pressure saturated with water vapour. The spirometer was frequently calibrated to ensure optimum performance. Observed values of FEV1 were expressed as percentages of predicted values. FEV1 was then divided into three groups. Mild obstruction [60\% - 79\%], moderate obstruction [40 59\%] and severe obstruction $[<40 \%]$.

\section{Health Related Quality of Life}

The Juniper AQLQ was used to assess the HRQL in this study. The instrument is an asthma specific questionnaire, which evaluates 32 items in four domains of health-related quality of life that are of importance to subjects with asthma: activity limitation (11 items), symptoms (12 items), emotional function (5 items) and exposure to environmental stimuli (4 items). The subjects have to choose five activities ( 5 items out of 11 in the activity domain) that they are bothered by or have problems with. A list of suggested activities is provided to help the subjects to choose. Subjects are asked to recall their experiences during the previous two weeks and respond to each item on a seven-point Likert scale. The overall AQLQ score is calculated as the mean for all 32 items. As there are no set classifications for the AQLQ-S scoring in our study, we have arbitrary divided the scoring into poor quality of life $(1-2.9)$, average quality of life (3 - 4.9) and good quality of life.5,6,7

Along with the above data co-variables such as age, sex, region of living, BMI, allergy, passive smoking, age of diagnosis of asthma and drug delivery devices were measured.

\section{Statistical Analysis}

The data obtained were represented in the form of Tables and Graphs. The data included frequencies and their percentages. The data of the present study was nominal, therefore Pearson's chi-square test was applied. The data was considered statistically significant at 95\% confidence interval. The data was analysed using SPSS version 11 .

\section{RESULTS}

In this study, 89 asthmatics who met the eligibility criteria were enrolled. The mean age of the population was 48.25 years with standard deviation of \pm 15.64 . Around $87.5 \%$ of 
population above 31 years of age were either overweight or obese, $77.77 \%$ of population above 30 years had moderate obstruction in spirometry and $83.33 \%$ of population above 30 years of age had an average quality of life. Severe obstruction was higher in females (68\%) as compared to males (32\%). $56.66 \%$ of population in our study with an average AQLQ score were having normal BMI. It is not statistically significant. $51.11 \%$ of population with history of passive smoking had moderate obstruction, though not statistically significant. $58.33 \%$ of patients with poor AQLQ scores gave history of passive smoking, though it is not statistically significant. $31.66 \%$ of patients were diagnosed to have asthma between 21 - 30 years who had an average quality of life and it is not statistically significant. $26.66 \%$ patients were having average quality of life and 52.9\% patients with good quality of life were using MDI with spacer and it was statistically significant. $85 \%$ patients with history of allergy had an average quality of life and it was statistically significant. $43 \%$ of patients with moderate obstruction had an average quality of life, though not statistically significant.

\begin{tabular}{|c|c|}
\hline Age & $48.25 \pm 15.643$ \\
\hline $18-30$ & $14(15.73 \%)$ \\
\hline $31-50$ & $32(32.95 \%)$ \\
\hline$>50$ & $11(48.31 \%)$ \\
\hline Male \% & $38(42.69 \%)$ \\
\hline Female \% & $51(57.30 \%)$ \\
\hline BMI & $24.069 \pm 4.043$ \\
\hline \multicolumn{2}{|l|}{ Region of Living } \\
\hline Urban & $48(53.93 \%)$ \\
\hline Rural & $41(46.06 \%)$ \\
\hline \multicolumn{2}{|l|}{ Age of Diagnosis } \\
\hline $0-10$ & $8(8.98 \%)$ \\
\hline $11-20$ & $16(17.97 \%)$ \\
\hline $21-30$ & $25(28.08 \%)$ \\
\hline $31-40$ & $22(24.71 \%)$ \\
\hline $41-50$ & $14(15.73 \%)$ \\
\hline$>50$ & $4(4.49 \%)$ \\
\hline \multicolumn{2}{|l|}{ Passive Smoking } \\
\hline Yes & $41(46.06 \%)$ \\
\hline No & $48(53.93 \%)$ \\
\hline \multicolumn{2}{|l|}{ Mode of Delivery } \\
\hline MDI & $28(33.73 \%)$ \\
\hline MDI with Spacer & $25(28.08 \%)$ \\
\hline DPI & $33(37.07 \%)$ \\
\hline Nebuliser & $3(3.37 \%)$ \\
\hline \multicolumn{2}{|l|}{ Allergy } \\
\hline Yes & $68(76.40 \%)$ \\
\hline No & $21(23.59 \%)$ \\
\hline Moderate Asthma & $19(21.34 \%)$ \\
\hline Severe Asthma & $70(78.65 \%)$ \\
\hline PEF & $3.65 \pm 1.59$ \\
\hline $\mathrm{FEV}_{1}, \mathrm{~L}$ & $1.32 \pm 0.644$ \\
\hline $\mathrm{FEV}_{1} \%$ & $48.31 \%$ \\
\hline AQLQ Score & $4.060 \pm 0.992$ \\
\hline \multicolumn{2}{|c|}{ Table 1. Characteristic of Study Population } \\
\hline
\end{tabular}

\begin{tabular}{|c|c|c|c|}
\hline $\mathbf{1 - 2 . 9}$ & $\mathbf{3 - 4 . 9}$ & $\mathbf{5 - 7}$ & \\
\hline $4(33.33 \%)$ & $23(38.33 \%)$ & $1(5.88 \%)$ & 28 \\
\hline 0 & $16(26.66 \%)$ & $9(52.94 \%)$ & 25 \\
\hline $7(58.33 \%)$ & $19(31.66 \%)$ & $7(41.17 \%)$ & 33 \\
\hline $1(8.33 \%)$ & $2(3.33 \%)$ & 0 & 3 \\
\hline 12 & 60 & 17 & 89 \\
\hline \multicolumn{4}{|c|}{ Table 2. Comparing Mode of Drug Delivery Device } \\
against Quality of Life \\
\hline
\end{tabular}

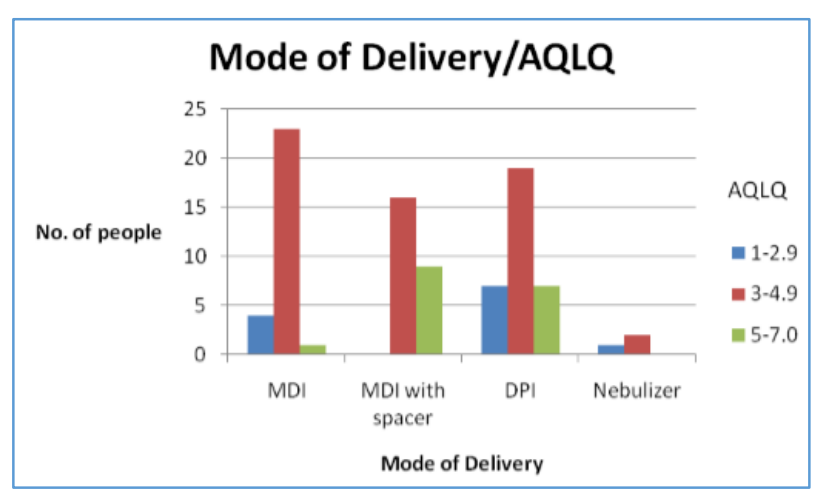

Chi-square 15.064, df 6, p $<0.05$

\begin{tabular}{|c|c|c|c|}
\hline $\mathbf{1 - 2 . 9}$ & $\mathbf{3 - 4 . 9}$ & $\mathbf{5 - 7}$ & \\
\hline $8(66.66 \%)$ & $51(85 \%)$ & $9(52.94 \%)$ & 68 \\
\hline $4(33.33 \%)$ & $9(15 \%)$ & $8(47.05 \%)$ & 21 \\
\hline 12 & 60 & 17 & 89 \\
\hline
\end{tabular}

Table 3. Correlation between Allergy and Quality of Life

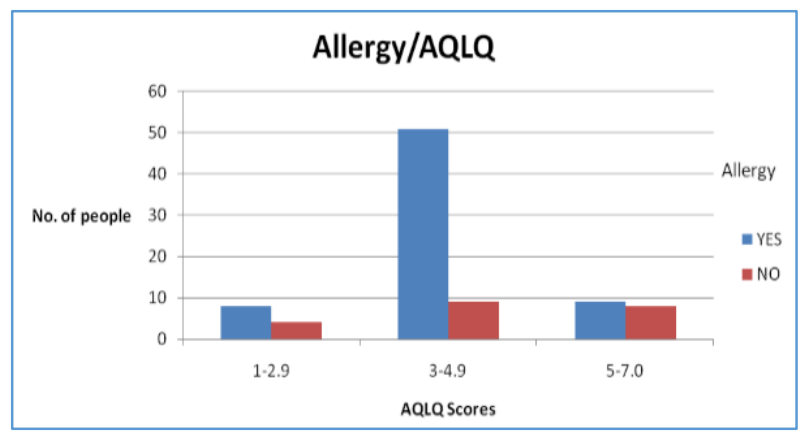

Chi-square 8.281, df $2, \mathrm{p}<0.05$

\begin{tabular}{|c|c|c|c|}
\hline $\mathbf{1 - 2 . 9}$ & $\mathbf{3 - 4 . 9}$ & $\mathbf{5 - 7}$ & \\
\hline $2(16.66 \%)$ & $18(30 \%)$ & $5(29.41 \%)$ & 25 \\
\hline $9(75 \%)$ & $26(43.33 \%)$ & $10(58.82 \%)$ & 45 \\
\hline $1(8.33 \%)$ & $16(26.66 \%)$ & $2(11.76 \%)$ & 19 \\
\hline 12 & 60 & 17 & 89 \\
\hline
\end{tabular}

Table 4. Association between FEV1 and Quality of Life

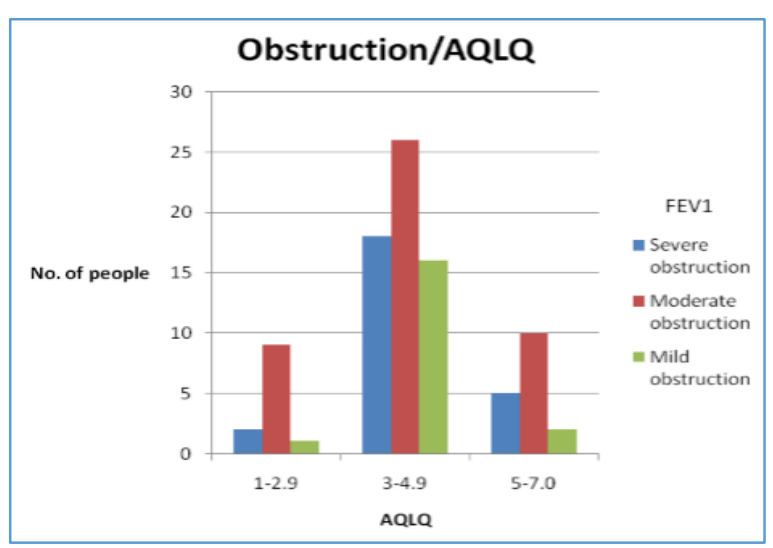

Chi-square 5.392, df 4, p > 0.05 


\section{DISCUSSION}

Asthma is a chronic disease that is prevalent in India. Outcomes of efficacy and effectiveness in asthma clinical trials and in clinical practice have focused on improvement in asthma control as measured by FEV1 and peak flow, symptom scores and requirement for the use of reliever medication with little attention to quality of life. With this study, we tried to determine the quality of life in adult patients with moderate-to-severe asthma.

The mean age of population in our study was 48.25 years with standard deviation of \pm 15 .64. The mean AQLQ-S score was 4.06. Observing the distribution of population in the study group, no major difference was seen in males and females in age group between 18 - 30 years. In the age group between 31 - 50 years, the total number of females [20 $(62.50 \%)]$ were more compared to males [12 (37.50\%)]. Similarly, in the study population above 50 years of age, the total number of females [24 (55.81\%)] were higher as compared to males [19 (44.18\%)]. This study thus shows that as age progresses, women are more affected by asthma as compared to men. These findings are consistent with a study by Watson et al.

When comparing age against Body Mass Index [BMI], it was found that [16(32\%)] patients in 31 - 50 age group and [27 (54\%)] patients above 50 years of age had normal BMI. Those in the study population who were overweight/ obese, majority of them [28 (87.5\%)] were above the age of 31 years. Similarly, when BMI was compared with quality of life score, [34 (56.66\%)] patients with average quality of life scores were having a normal BMI. The above findings are not statistically significant. In a study by E. Nadi et al ${ }^{12}$ majority of his study population (54.87\%) had normal weight (BMI, 1925.9), (36.34\%) of patients were either overweight (BMI, 26 to 29.9 ) or obese (BMI > 30; 14.57\%) and $(8.79 \%$ ) were underweight $(\mathrm{BMI}<19)$. These findings are consistent with our study.

In this study, when age of patients was compared against FEV1, [35 (77.77\%)] of population with moderate obstruction and [23 (92\%)] of the patients with severe obstruction were above the age of 30 years. Though this was not statistically significant, it does show that lung function of asthmatics do deteriorate as age progresses. In a study by Kupczyk et al,13 it was seen that asthmatic patients develop a progressive decline in pulmonary function correlated with age, sex, duration of asthma and asthma severity. Age of patient was then compared against AQLQ-S score. Here on, the one hand [50 (83.33\%)] of population above 30 years of age had an average quality of life and on the other hand among those with good quality of life [15 (88.23\%) were above 30 years of age. There are currently no data to support the above findings. Thus unlike lung function testing, quality of life scoring was variable with age.

In this study when comparing the lung function tests of men and women, [21 (46.66\%)] men and [24 (53.33\%)] women had moderate obstruction. Severe obstruction was higher in women [17 (68\%)] compared to men [8 (32\%)] and the above findings are not statistically significant. There is lack of data and clarity with regard to whether men or women suffer worse symptoms and greater deficits of lung function. There is need for further studies concerning possible gender differences in airway remodelling.
In this study, we tried to find out whether passive smoking has a role in asthma. Passive smoking was first compared with lung function [FEV-1]. Here [23 (51.11\%)] of patients with moderate obstruction gave history of passive smoking, while [11 (44\%)] patients who had severe obstruction on their pulmonary function test were passive smokers. The above data is not statistically significant. Similarly, when passive smoking as compared against quality of life scores [7(58.33\%)] of patients with poor AQLQ-S scores gave history of passive smoking and this data is not statistically significant. Currently, there are no studies which show that exposure to ETS is associated with an increased risk of adult onset asthma with worsening of respiratory symptoms and lung function in adult asthmatics.

Role of age at which asthma was diagnosed and its effect on quality of life was assessed. Here [19 (31.66\%)], patients who were diagnosed to have asthma between the age group of 21 - 30 years had an average quality of life and this is not statistically significant. There is currently no study to support our findings.

In this study [16 (26.66\%)], patients with average quality of life and [9 (52.9\%)] patients with good quality of life were using MDI with spacer and this is statistically significant. In our study, MDI with spacer fared better compared to the other devices. The reasons may be less patient coordination is required, simpler usage technique. Though lack of portability and higher cost than MDI or DPI alone make this device less favourable among patients.

In a study by Dolovich et al published in chest journal ${ }^{14}$ which compared the various devices, it was found that there was no difference between devices in terms of efficacy outcome. Each of the delivery device provided similar outcome in patients using the correct technique for inhalation.

In this study when presence of allergy was compared with quality of life scores [51 (85\%)], patients with average quality of life and [8 (66.66\%)] of study population with poor quality of life gave history of allergy and this is statistically significant. Longitudinal studies of the outcome of childhood asthma have shown atop to be a major risk factor for asthma persisting into adult life.15,16,17 In a study by Benedicte Leynaert et al, subjects with allergic rhinitis plus asthma had a greater impairment of physical functioning. 18

In the end lung function was compared with AQLQ-S scores, [26 (43\%)] of subject population with moderate obstruction were found to have an average quality of life and this is not statistically significant. In a study done by Juniper et $\mathrm{al}^{19}$ it was found that lung function was not an independent predictor or determinant of Health Related Quality of Life [HRQL] at any level of asthma severity. Similarly, in a study done by Syifa Imelda et al it was concluded that the quality of life with lung function test had weak correlation.

\section{CONCLUSION}

Though, it is very clearly understood that patients with chronic asthma suffer from poor quality of life at one point of time, there is dearth of literature on these findings. The poor quality of life in these patients may be because of poor understanding of the disease, improper medications, stigma associated with the disease, poor adherence to medications, 
improper inhaler technique, associated conditions such as allergic rhinitis and GERD.

In our study we compared age, age of diagnosis of asthma, BMI passive smoking, allergy, drug delivery devices and lung function testing (FEV-1) against quality of life scoring (AQLQS) score.

Though the findings were not statistically significant, the data from the study belonged to average to poor quality of life. This warrants further study with a larger sample size. Further studies should be directed towards conducting a prospective trial directed at assessing quality of life of patients at a regular interval.

Thus, from this above study, it can be stated that traditional measures of asthma severity and asthma control explain only half of the variance of HRQL. If we are to maximise the ability of our patients to live with their asthma, we need to prospectively delineate the entire array of contributors to HRQL in patients with asthma.

\section{Recommendations}

1. In addition to clinically assessing asthmatic patients, Quality of Life using appropriate scales should be incorporated in the regular clinical assessment of patients.

2. It is essential to identify factors that lead to poor quality of life in the patient and appropriate corrective measures should be taken.

3. The treatment should be individualised, appropriate drug delivery device should be prescribed and technique should be explained in lucid language.

4. In every follow-up, compliance to treatment and technique of use of drug delivery system should be assessed and corrected accordingly.

5. Associated determinants of asthma should be identified and treated accordingly.

\section{REFERENCES}

[1] Burney P. The changing prevalence of asthma? Thorax 2002;57(Suppl ii):ii36-9.

[2] Peat JK, van den Berg RH, Green WF, et al. Changing prevalence of asthma in Australian children. BMJ 1994;308(6944):1591-6.

[3] Robertson CF, Heycock E, Bishop J, et al. Prevalence of asthma in Melbourne schoolchildren: changes over 26 years. BMJ 1991;302(6785):1116-8.

[4] Baker DF, Marks GB, Poulos LM, et al. Review of proposed national health priority area asthma indicators and data sources. AIHW cat. no. ACM 2. 2004. Available at www.asthmamonitoring.org. Canberra: AIHW.

[5] Heaney LG, Robinson DS. Severe asthma treatment: need for characterising patients. Lancet 2005;365(9463):974-6.
[6] Chanez P, Wenzel SE, Anderson GP, et al. Severe asthma in adults: what are the important questions? J Allergy Clin Immunol 2007;119(6):1337-48.

[7] Proceedings of the ATS workshop on refractory asthma: current understanding, recommendations, and unanswered questions. American Thoracic Society. Am J Respir Crit Care Med 2000;162(6):234151.

[8] Global Initiative for Asthma. National Heart and Lung Institute, National Institutes of Health USA, and the World Health Organization. http://www.ginasthma.org. Ref Type: Generic.

[9] Moore WC, Bleecker ER, Curran-Everett D, et al. Characterization of the severe asthma phenotype by the national heart, lung, and blood institute's severe asthma research program. J Allergy Clin Immunol 2007;119(2):405-13.

[10] The ENFUMOSA cross-sectional European multicentre study of the clinical phenotype of chronic severe asthma. European network for understanding mechanisms of severe asthma. Eur Respir J 2003;22(3):470-7.

[11] Gusbin N, Garzaniti N, Louis R. Asthma and tobacco. Rev Med Liege 2006;61:81-6.

[12] Nadi E, Zeraati F, Ansari M, et al. Association of asthma severity with body mass index among adults. Acta Medical Iranica 2007;45(5):383-8.

[13] Kupczyk M, Kupryś I, Górski P, et al. Long-term deterioration of lung function in asthmatic outpatients. Respiration 2004;71(3):233-40.

[14] Dolovich MB, Ahrens RC, Hess DR, et al. Device selection and outcomes of aerosol therapy: evidencebased guidelines: American College of Chest Physicians/American College of Asthma, Allergy, and Immunology. Chest 2005;127(1):335-71.

[15] Strachan DP, Butland BK, Anderson HR. Incidence and prognosis of asthma and wheezing illness from early childhood to age 33 in a national British cohort. BMJ 1996;312(7040):1195-9.

[16] Godden DJ, Ross S, Abdalla M, et al. Outcome of wheeze in childhood. Symptoms and pulmonary function 25 years later. Am J Respir Crit Care Med 1994;149(1):106-12.

[17] Kokkonen J, Linna O. The state of childhood asthma in young adulthood. Eur Respir J 1993;6(5):657-61.

[18] Leynaert B, Neukirch C, Liard R, et al. Quality of life in allergic rhinitis and asthma. A population-based study of young adults. Am J Respir Crit Care Med 2000;162(4 Pt 1):1391-6.

[19] Moy ML, Israel E, Weiss ST, et al. Clinical predictors of health-related quality of life depend on asthma severity. Am J Respire Crit Care Med 2001;163(4): 924-9. 